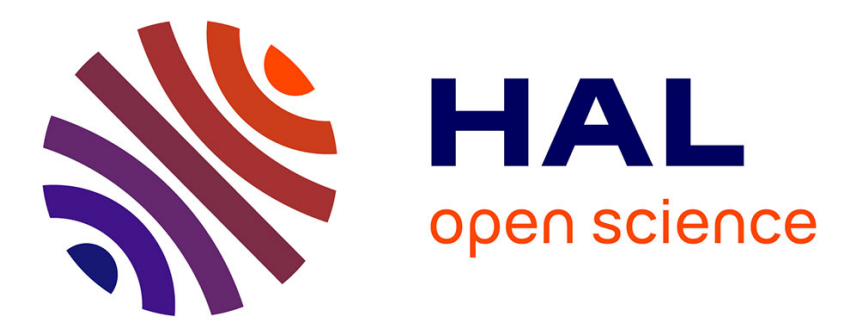

\title{
Interactive Toys in the Home: A Parents Perspective
}

Omar Mubin, Duncan Rutishauser, Mauricio Novoa, Derek Wainohu, Suleman

Shahid

\section{To cite this version:}

Omar Mubin, Duncan Rutishauser, Mauricio Novoa, Derek Wainohu, Suleman Shahid. Interactive Toys in the Home: A Parents Perspective. 15th Human-Computer Interaction (INTERACT), Sep 2015, Bamberg, Germany. pp.573-577, 10.1007/978-3-319-22723-8_64 . hal-01610844

\section{HAL Id: hal-01610844 \\ https://hal.inria.fr/hal-01610844}

Submitted on 5 Oct 2017

HAL is a multi-disciplinary open access archive for the deposit and dissemination of scientific research documents, whether they are published or not. The documents may come from teaching and research institutions in France or abroad, or from public or private research centers.
L'archive ouverte pluridisciplinaire HAL, est destinée au dépôt et à la diffusion de documents scientifiques de niveau recherche, publiés ou non, émanant des établissements d'enseignement et de recherche français ou étrangers, des laboratoires publics ou privés.

\section{(c)(1)}

Distributed under a Creative Commons Attribution| 4.0 International License 


\title{
Interactive Toys in the Home: A Parents Perspective
}

\author{
Omar Mubin ${ }^{1}$, Duncan Rutishauser ${ }^{1}$, Mauricio Novoa ${ }^{1}$, Derek Wainohu ${ }^{2}$, and \\ Suleman Shahid ${ }^{3}$ \\ ${ }^{1}$ University of Western Sydney; Australia, ${ }^{2}$ InfaSecure Private Limited; Australia, \\ ${ }^{3}$ Tilburg center for Cognition and Communication, Tilburg University; The \\ Netherlands
}

\begin{abstract}
In our research we argue for the benefits of Learning through play. In this initial design case, we report on on the general requirements of household educative and interactive toys and current usage practices via a focus group with parents. Our results indicate that the parents in our focus group held greatest importance to social and physical play and wished to reduce the dependency on electronic devices.
\end{abstract}

Keywords: Tangible Interfaces, Learning through Play

\section{Introduction}

In this paper we report on our early research efforts that contribute towards a larger venture that we term as Learning by Interactive Play. Learning by Interactive Play is the development of design intervention for better education, by integrating an enjoyable and recreational method of Play. Advances in technology have opened opportunities to create interfaces that promote conventional learning components (such as tangible interaction) complemented with a variety of interaction techniques, styles, modalities and tools [3]. Within Human Computer Interaction research, there are also significant new, post-digital developments, exemplified by the new surge of board games (including hybrids with digital elements), motion detection technology in console gaming (especially Wii) and location-based mobile and pervasive games.

However, touch screens and socially exclusive play have become commonplace with tablets and gaming consoles in the home and school. It is becoming too easy to produce a toy that fosters distraction without involving the essential components of learning; such as: social interaction, parent/peer involvement, physical manipulation/movement and experience based learning. Vygotsky [10] recognised the significance of adults and peers in extending a childs learning. Known as the Zone of proximal development, the belief that help provided to a child by parents/peers through stages of difficulty to ensure they do not get stuck allows them to continue to learn and eventually be able to complete the task independently. The importance of parents in the development of learning abilities in children has been advocated [6] but the involvement of parents and 
their preferences/requirements in the design processes of interactive educative products has been limited in prior literature. One study which supports our view point of involving parents is [9], where the role of parents and teachers as expert users during the design process is strongly emphasized. Parents are the key peers/partners while the children interact with toys at home and hence need to be involved in the design process. In the initial phases of our research we have focused on interactive educative toys to be used at home by pre-schoolers (3-6 years old). In this paper we report on an initial elicitation of design requirements and current usage practices of interactive educational toys through a focus group with parents to ultimately drive concept development in the area of Learn through Play. In conclusion we synthesize our findings which we aim to feed back into our design process and to further drive the design of new concepts and prototypes.

\section{Focus Group with Parents}

A focus group with parents ( $\mathrm{N}=7$ mothers; voluntarily recruited, each having at least one pre-schooler child) was conducted to firstly gain background information, preferences and requirements about the user group (pre-schoolers) through parents. Ethics clearances to conduct the focus group were attained from the host institution.

\subsection{Procedure}

After obtaining consent from the 7 mothers the facilitator gave a brief summary of the agenda of the focus group which was followed by a presentation about the project vision. In the focus group, questions were asked regarding the requirements of interactive educative toys at home.

\subsection{Setup and Measurements}

The participants were seated around a central table in a room.Opinion based qualitative data was recorded, via audio and notes by the facilitator. Open ended questions were used to facilitate the discussion. Themes that were addressed in the focus group included: goals when purchasing, child benefits, independent vs. combined learning, operation, aesthetics, size and shape.

\subsection{Results}

The majority of mothers in our focus group stated to have bought educational toys but more often that not they thought of the educational value as a bonus. When purchasing educative toys the features that the mothers would look for included: ease of use, allowances for motor skills development, uni-sex, animated through music or sound, not entirely an electronic/digital interface, possibilities to engage in social play with peers, etc. Discussion around tablets and iPads 
was interesting and figured fairly regularly in the focus group. Many mothers wished to see more physically open interfaces combining both digital and tactile components as Tablets were already being used regularly at pre-school. One mother was quoted to say: I'll be honest, mine(iPad) is a babysitter for my X (name of son). One of the key benefits of tablets that was presented by the mothers was minimal start up/set up; i.e. so simple that the children could do it themselves. Some mothers also commented that they preferred customisable toys/interfaces so that the younger children could jointly play with their younger or older siblings.

By synthesizing the discussion with the mothers we concluded that there were two types of play in a common household; namely 1. Toys/games that are used to entertain a child or busy them allowing a parent to do daily tasks freely; OR 2. Specifically set time where learning, imagination and exploration is encouraged. More often than not the first is used in a busy household, with tablets and games/apps, it is generally quick and easy, requires little space and minimal explanation/introduction to the child. While not ideal for learning it serves the purpose for most of the mothers day to day routine; as exemplified by the following quote: we use ours in the morning, they have their breakfast and then they get their iPads for 20mins, while I run around cleaning up, and packing schools bags. The second mode was said to be typically used at set aside times where open play by the children was encouraged, as evidenced by one mother's statement: I like to create a space with a lot of toys, and they can just do a round robin, a little bit of drawing here some play doh here.

All mothers in our focus group unanimously agreed that they would like to play a much more active role in any play sessions while maintaining the child's independence. The mothers believed that by playing an active role they could also introduce language in the game play; for e.g. It is good for them to be independent, however I love having the option of doing something with them. In the conclusion of Session 1 there were some discussions on aesthetics of educative toys, with terms such as sustainability popping up. Preference towards uni-sex but also monochrome colors was also put forward.

\section{Discussion and Conclusion}

Our experiences with the focus group indicated that the mothers whom we interviewed put forward an emphasis on attributes such as social play, supportive play, open and uninhibited play, endorsing physicality, avoiding a complete emphasis on digitization, etc. These attributes and the vision that they initiate are shared by our research team and we look forward to further advance our design ideas based on the feedback attained. Our results portray that parents realise the importance of joint play; i.e. using playtime as a connection pathway between parent and learning child, introducing language as a support tool and letting the child explore the play space independently. Examples of the role of parents in a supporting capacity during the learning process of the child can be found in prior work [5]. Other insights presented in prior work [7] support our assertion 
that parents should be at hand to facilitate setup/training and guide interaction. Eventually, social play can not only involve parents but also peers. Our findings also indicate the importance of physical play via tangible elements and consequently combining both digital and analog mediums to facilitate a move away from purely graphical or electronic interfaces such as tablets. The merge of digital and analog as two aspects in play and learning has been discussed in prior work [4]. Most of the mothers acknowledged the importance of tablets such as iPads however wished to see more of social and physical play. Tablets such as iPads are tailored to be used individually and the nature of the devices does not support the child to be easily observed or supported by peer or parent [8]. The mothers in our focus group also indicated that they preferred toys that would assist in open gameplay, minimizing rules and allowing for exploration and creativity; elements also advocated in prior research [1].

We acknowledge that our results are inferred from a single focus group with Australian mothers. Literature [2] informs us that culture and the personality of mothers will play a significant role in the interpretation of what constitutes learning by playing. Taking this into account, in the future we aim to run more user research sessions whilst developing our prototypes and concept ideas further within our project of learning through play.

\section{References}

1. Bekker, T., Sturm, J., Wesselink, R., Groenendaal, B., Eggen, B.: Interactive play objects and the effects of open-ended play on social interaction and fun. In: Conference on Advances in Computer Entertainment Technology. pp. 389-392. ACM (2008)

2. Fisher, K.R., Hirsh-Pasek, K., Golinkoff, R.M., Gryfe, S.G.: Conceptual split? parents' and experts' perceptions of play in the 21st century. Journal of Applied Developmental Psychology 29(4), 305-316 (2008)

3. Greener, S.: Smart toys and sophisticated learning tools. Interactive Learning Environments 22(5), 549-550 (2014)

4. Heibeck, F.: Cuboino: extending physical games. an example. In: CHI'13 Extended Abstracts on Human Factors in Computing Systems. pp. 2935-2938. ACM (2013)

5. Horn, M.S., Solovey, E.T., Crouser, R.J., Jacob, R.J.: Comparing the use of tangible and graphical programming languages for informal science education. In: Conference on Human Factors in Computing Systems. pp. 975-984. ACM (2009)

6. O'Hara, M.: Young children's ict experiences in the home: Some parental perspectives. Journal of Early Childhood Research pp. 220-232 (2011)

7. Plowman, L., McPake, J.: Seven myths about young children and technology. Childhood Education 89(1), 27-33 (2013)

8. Plowman, L., Stephen, C.: Guided interaction: Exploring how adults can support children's learning with technology in preschool settings. Hong Kong Journal of Early Childhood 12(1), 15-22 (2013)

9. Robins, B., Ferrari, E., Dautenhahn, K.: Developing scenarios for robot assisted play. In: Symposium on Robot and Human Interactive Communication. pp. 180 186. IEEE (2008)

10. Tudge, J.: Vygotsky, the zone of proximal development, and peer collaboration: Implications for classroom practice. (1992) 